\title{
An improved and commercially viable process for the preparation of Alfuzosin hydrochloride
}

\author{
Manne Satyanarayana Reddy*a , Bairy Kondal Reddy ${ }^{a}$, Chepyala Kista Reddy \\ Muppa Kishore Kumar ${ }^{a}$, Srinivasan Thirumalai Rajan ${ }^{a}$ and Venkatesh Mummadi ${ }^{a}$ \\ ${ }^{a}$ Department of Research and Development, MSN Laboratories Limited Survey No. 317 and 323, \\ Rudraram, Patancheru, Medak District - 502 329, Andhra Pradesh, India \\ ${ }^{b}$ Department of Chemistry P.G College of Science Saifabad, Hyderabad, India \\ E-mail:1rmsnl@yahoo.co.in,drmsnreddy@msnlabs.com
}

\begin{abstract}
Alfuzosin, is a potential anti-hypertensive agent, mainly used for the treatment of the lower urinary apparatus. An highly efficient, inexpensive, eco-friendly, and commercially viable synthetic process for this drug has been discussed.
\end{abstract}

Keywords : Alfuzosin, antagonist, quinazoline and $\alpha_{1}$-adrenergic receptors

\section{Introduction}

Alfuzosin is a potent drug for the treatment of cardiovascular disorders, ${ }^{1,2}$ which is marketed under the brand name of Uroxatral. It is an antagonist of vascular $\alpha_{1}$-adrenergic receptors and used for the treatment of all forms of genuine or secondary hypertensive disorders. Cardiovascular diseases are a global problem. In the developed world, its prevalence is linked to our increasingly unhealthy lifestyle, with risk factors including lack of exercise, overweight and obesity, and smoking. These are also linked to diabetes which greatly increases the risk of developing a heart disease.

To meet the Alfuzosin drug demand of the market, there is a need to develop an ideal commercial process, which is a safe, ecologically sound, economic and meets the quality specifications. The reported synthetic processes ${ }^{1}$ for Alfuzosin involves four stages and suffer from the disadvantage of low yields, high pressure, expensive reagents, which are not feasible for industrial scale up. Our quest to develop a more economic and cost effective process for important API's, ${ }^{3,4}$ prompted us to develop a process for Alfuzosin. 


\section{Results and Discussion}

Our research work focuses on the design of a commercial viable process and optimizing all parameters of the reactions that are involved in the synthesis of Alfuzosin ${ }^{3}$. Based on a literature search, we designed the synthesis as illustrated below.

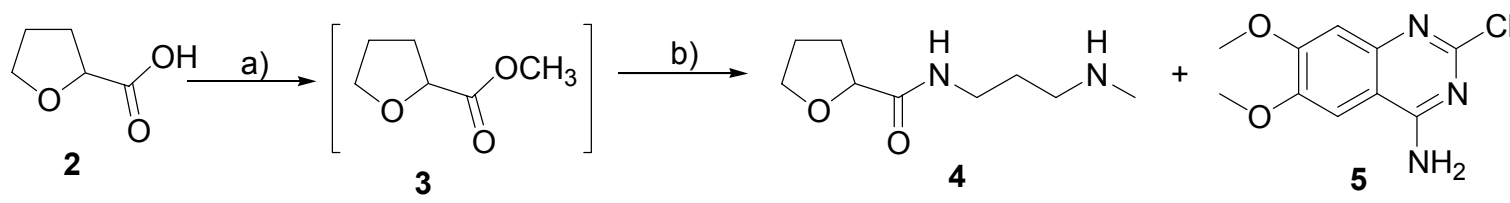

c)
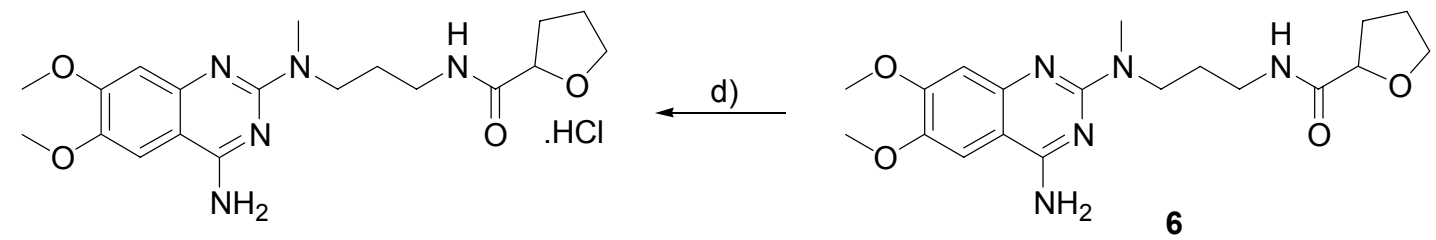

1

Scheme 1. Reagents and conditions : (a) Methanol/Sulfuric acid at $25-35^{\circ} \mathrm{C}$; (b) $N$-methyl propane 1,3-diamine, Methanol at $40-45^{\circ} \mathrm{C}$, (c) Isoamylalcohol at reflux temperature (d) Methanolic hydrochloride/Ethylacetate at $60-65^{\circ} \mathrm{C}$.

Accordingly, our first priority was to prepare tetrahydro- $N$-(3-(methylamino)propyl)furan-2carboxamide 4. Initial attempt to synthesize 4 by treating tetrahydro-2-furoic acid with thionyl chloride to get tetrahydro-2-furoyl chloride, followed by condensation with $N$-methyl propane 1,3-diamine ended up with the formation of a dimer of tetrahydro-2-furoic acid ${ }^{1}$ and other unknown impurities. Then, we thought esterification followed by condensation with $N$-methyl propane 1,3-diamine would solve the problem of the dimer formation. Therefore, we have esterified tetrahydro-2-furoic acid with methanol in presence of sulfuric acid and obtained the methyl ester of tetrahydro-2-furoic acid in $>99 \%$ purity but with less yield $(70 \%)$, due to the codistillation of the compound with methanol. To avoid this problem and to improve the yield, the condensation was carried out with $N$-Methyl propane 1,3-diamine in the same reaction medium without distilling methanol and this resulted in a good yield $(95 \%)$ of tetrahydro- $\mathrm{N}-(3-$ (methylamino)propyl)furan-2-carboxamide 4. This compound can also be prepared alternatively by reaction of $\mathrm{N}$-methyl propane 1,3-diamine with tetrahydro-2-furoic acid in the presence of a catalytic amount of boric acid by azeotropic removal of water.

After the successful optimization of stage 1, the priority was to condense tetrahydro- $\mathrm{N}-(3-$ (methylamino)propyl)furan-2-carboxamide 4 with 4-amino-2-chloro-6,7-dimethoxyquinazoline 5 to get compound $\mathbf{6}$. We tried the condensation in isoamyl alcohol at reflux temperature for 12- 
13 hours, but resulted in a poor quality material (93\%). Then we thought to isolate the product using acetone and got a slight improvement in the purity, but the color of the material was light brown. When we characterized the isolated material and found that the product was Alfuzosin hydrochloride salt 1, but not the Alfuzosin free base 6. Since the isolated compound was Alfuzosin hydrochloride salt, we dissolved the obtained compound in water and treated it with the carbon to improve the color of the product. It was converted into Alfuzosin free base by adjusting the $\mathrm{pH}$ of the reaction mixture with sodium hydroxide in a water-acetone mixture and filtered the Alfuzosin free base 6. To further improve the color and purity of the Alfuzosin free base, recrytallisation was attempted in different solvents and there mixture of solvents like methylene chloride, acetonitrile, tetrahydrofuran and ethyl acetate, but high purity $99.99 \%$ was achieved using ethyl acetate as solvent.

The final stage was to convert free base 6 to its hydrochloride salt 1. Initially, Alfuzosin free base dissolved in methanolic hydrochloride, was cooled to get precipitation and was filtered. The resulting compound was the methanol solvate form of Alfuzosin hydrochloride, (RS/OVI ${ }^{6}$ (i.e., residual solvents/organic volatile impurities) shows about 30,000 ppm of methanol). We replaced the solvent with isopropyl alcohol and ended up with the isopropyl alcohol solvate form of Alfuzosin hydrochloride, (RS/OVI shows about 20,000 ppm of isopropyl alcohol). To overcome the RS/OVI problem and to meet the ICH guidelines, we evaluated different solvents and ended up with the corresponding solvate forms of Alfuzosin hydrochloride. Then we thought to prepare Alfuzosin acetate by treatment with acetic acid and then converting it into its hydrochloride salt by treatment with ethyl acetate hydrochloride. This modification resulted in non-solvated Alfuzosin hydrochloride, but degradation of Alfuzosin hydrochloride was observed due to the presence of acetic acid traces in Alfuzosin hydrochloride. Degradation of Alfuzosin hydrochloride into $N$-(4-amino-6,7-dimethoxyquinazolin-2-yl)- $N$-methyl propane-1,3-diamine in the presence of an acid has been found by a HPLC technique. Finally, the problem was overcome by dissolving the Alfuzosin base in methanolic hydrochloride, saturated with ethyl acetate as an anti solvent, which was then filtered to get highly pure Alfuzosin hydrochloride. This was again mixed with ethyl acetate and stirred for a while to reduce the level of methanol solvate to obtain non-solvated anhydrous Alfuzosin hydrochloride 1. The final physical parameter, the water content of Alfuzosin hydrochloride is around $0.5 \%$ which shows the anhydrous nature of obtained Alfuzosin hydrochloride. ${ }^{5}$

\section{Conclusions}

In conclusion, we have developed an improved three step, inexpensive, and industrially scalable protocol for the synthesis of the anti hypertensive drug Alfuzosin hydrochloride, which can provide high throughputs and high quality product in each stage. 


\section{Experimental Section}

General Procedures. The ${ }^{1} \mathrm{H}$ and ${ }^{13} \mathrm{C}$ NMR spectra were recorded in $\mathrm{CDCl}_{3}$ and DMSO, using 300 and $50 \mathrm{MHz}$, respectively, on a Siemens $200 \mathrm{MHz}$ FT NMR spectrometer; the chemical shifts are reported in $\delta \mathrm{ppm}$ relative to TMS. The FT-IR spectra were recorded in the solid state as $\mathrm{KBr}$ dispersion using Thermo nicolet 380 model infrared spectrophotometer. The mass spectrum $(70 \mathrm{eV})$ was recorded on HP-5989A LC-MS spectrometer. The CHN analysis was carried out on a Perkin-Elmer model 2400S analyzer. The melting points were determined by using the capillary method on a POLMON (model MP-96) melting point apparatus. Analysis of the related substances by HPLC is carried out using a liquid chromatograph equipped with a variable wavelength UV-detector and integrator as apparatus with an Inertsil ODS-2, 150 X 4.6 $\mathrm{mm}, 5 \mu \mathrm{m}$ or equivalent column at a flow rate of $1.5 \mathrm{ml} / \mathrm{min}$ at $254 \mathrm{~nm}$ and at an ambient temperature using isocratic elution, runtime is 60 minutes, mobile phase is buffer (800) : acetonitrile (200) : tetrahydrofuran (10). The solvents and reagents were used without further purification.

Preparation of tetrahydro- $\mathrm{N}$-(3-(methylamino)propyl)furan-2-carboxamide (4). To a solution of tetrahydrofuran-2-carboxylic acid (2) $(35.0 \mathrm{~kg}, 1.0 \mathrm{~mol}$ equiv.) and methanol (350 L), conc. sulphuric acid was added $(1.68 \mathrm{~L}, 0.1 \mathrm{~mol}$ equiv.) and the resulting solution was stirred at 25 to $35^{\circ} \mathrm{C}$ for 4 hours. $N$-methyl propane 1,3 -diamine $(29.47 \mathrm{~kg})$ was then added and the mixture stirred for a further 36 hours at 40 to $45^{\circ} \mathrm{C}$. The reaction mixture was then concentrated removing methanol, via distillation at atmospheric pressure, whereupon isopropyl alcohol (175 L) was added and stirred for $45 \mathrm{~min}$. Filtration to remove the undesired inorganic waste followed by concentration of the filtrate, under reduced pressure, and further filtration at $25^{\circ} \mathrm{C}$ afforded (4) $(54.50 \mathrm{~kg}, 97.14 \%)$.

${ }^{1} \mathrm{H}$ NMR $\left(\mathrm{CDCl}_{3}\right): \delta 8.1(\mathrm{~s}, 1 \mathrm{H}), 4.75(\mathrm{t}, 1 \mathrm{H}), 3.6-3.8(\mathrm{~m}, 2 \mathrm{H}), 3.1(\mathrm{t}, 2 \mathrm{H}) 2.65(\mathrm{t}, 2 \mathrm{H}), 2.47(\mathrm{~s}$, $3 \mathrm{H}), 2.0(\mathrm{~s}, 1 \mathrm{H}), 1.9-2.21(\mathrm{~m}, 2 \mathrm{H}), 1.8-1.9(\mathrm{~m}, 2 \mathrm{H}), 1.72(\mathrm{~m}, 2 \mathrm{H}) ;{ }^{13} \mathrm{C} \mathrm{NMR}: \delta 172.1,84.7,70.2$, 49.2, 38.1, 36.1, 31.9, 29, 24.9; $\mathrm{MS}: \mathrm{m} / \mathrm{e}=186 \mathrm{M}^{+}$.

Preparation of $\mathrm{N}$-1-(4- Amino-6,7-dimethoxyquinozol-2-yl)- $\mathrm{N}-1$-methyl- $\mathrm{N}-2-$ (tetrahydrofuroyl-2)-propylenediamine (6). A suspension of 4-amino-2-chloro-6,7dimethoxyquinazoline (5) (17.5 kg, 1.0 mol equiv.), tetrahydro- $N$-(3-(methylamino)propyl)furan2-carboxamide (4) (19.93 kg, $1.3 \mathrm{~mol}$ equiv.) and isoamyl alcohol $(53 \mathrm{~L})$, was heated to reflux and stirred for 12 hours at 110 to $120^{\circ} \mathrm{C}$. The reaction mixture was then concentrated removing the isoamyl alcohol, via distillation under reduced pressure at 100 to $110^{\circ} \mathrm{C}$. The reaction mixture was then cooled to 50 to $55^{\circ} \mathrm{C}$, acetone was added $(10 \mathrm{~L})$ and the solvent was distilled off completely under reduced pressure at 50 to $55^{\circ} \mathrm{C}$. Then, acetone $(35 \mathrm{~L})$ was added again and cooled to 25 to $35^{\circ} \mathrm{C}$, stirred for 45 minutes, and was followed by filtration of the compound. The wet compound was dissolved in water $(175 \mathrm{~L})$, carbon treatment was given to the compound with $1.75 \mathrm{~kg}$ of acidic carbon. Acetone $(70 \mathrm{~L})$ was added to the water and the $\mathrm{pH}$ of the reaction mixture adjusted to 12 to 14 with $20 \%$ sodium hydroxide solution $(20 \mathrm{~L})$ at 10 to $15^{\circ} \mathrm{C}$ and stirred 
for 8 to 9 hours. Filtration of the compound and taking up the wet compound in ethyl acetate (88 L) was followed by heating of the mass to 70 to $75^{\circ} \mathrm{C}$. The mass was then stirred at 70 to $75^{\circ} \mathrm{C}$ for 45 minutes and then cooled to 0 to $5^{\circ} \mathrm{C}$. Filtration of the solid and washing with ethyl acetate afforded $\quad N$-1-(4-amino-6,7-dimethoxyquinazol-2-yl)- $N$-1-methyl- $N$-2-(tetrahydrofuronyl-2)propylene diamine (6) $(20.74 \mathrm{~kg}, 72.89 \%)$.

Melting range : $178-180^{\circ} \mathrm{C} .{ }^{1} \mathrm{H}$ NMR $\left(\mathrm{CDCl}_{3}\right): \delta 8.15(\mathrm{~s}, 1 \mathrm{H}), 7.45(\mathrm{~s}, 1 \mathrm{H}), 7.3(\mathrm{~s}, 1 \mathrm{H}), 4.69(\mathrm{~m}$, $1 \mathrm{H}), 3.6-3.8(\mathrm{~m}, 2 \mathrm{H}), 3.73(\mathrm{~s}, 6 \mathrm{H}), 3.15(\mathrm{t}, 2 \mathrm{H}), 3.0(\mathrm{t}, 2 \mathrm{H}), 2.47(\mathrm{~s}, 3 \mathrm{H}), 2.35(\mathrm{~s}, 2 \mathrm{H}), 1.96-2.21$ $(\mathrm{m}, 2 \mathrm{H}), 1.8-1.9(\mathrm{~m}, 2 \mathrm{H}), 1.75(\mathrm{~m}, 2 \mathrm{H}) ;{ }^{13} \mathrm{C}$ NMR : $\delta 183.2,172.1,161.6,158.8,148.7,148.3$, 114.9, 107.1, 102.6, 84.7, 70.2, 56.2, 56.2, 50.7, 38.4, 38.1, 31.9, 26.4, 24.9; MS : m/e=389 $\mathrm{M}^{+}$.

Preparation of $\quad \mathrm{N}$-1-(4-Amino-6,7-dimethoxyquinozol-2-yl)- $\mathrm{N}$-1-methyl- $\mathrm{N}-2$ (tetrahydrofuroyl-2)-propylenediamine hydrochloride compound of formula (1). A methanolic hydrochloride solution (13 L) (assay 8.81\%) was slowly added to a suspension of $N$ 1-(4-amino-6,7-dimethoxyquinazol-2-yl)- $N$-1-methyl- $N$-2-(tetrahydrofuronyl-2)-propylene diamine (6) $(13 \mathrm{~kg})$ and methanol $(65 \mathrm{~L})$ at 25 to $35^{\circ} \mathrm{C}$. The reaction mixture was heated to 60 to $65^{\circ} \mathrm{C}$ followed by filtration through high flow (Celite). The resulting filtrate was added to ethyl acetate $(195 \mathrm{~L})$ at 25 to $35^{\circ} \mathrm{C}$ and was stirred for 60 minutes. After filtration of the solid, the wet solid was again taken up in ethyl acetate $(195 \mathrm{~L})$, heated to reflux and stirred for 30 minutes. Filtration of the solid to get the title compound followed by drying of the compound at 100 to $110^{\circ} \mathrm{C}$, milling and sifting led to anhydrous Alfuzosin hydrochloride (1) (13.5 kg, 94.95\%).

Melting range : $230-232^{\circ} \mathrm{C} .{ }^{1} \mathrm{H}$ NMR $\left(\mathrm{CDCl}_{3}\right): \delta 8.2(\mathrm{~s}, 1 \mathrm{H}), 7.41(\mathrm{~s}, 1 \mathrm{H}), 7.24(\mathrm{~s}, 1 \mathrm{H}), 4.72(\mathrm{~m}$, $1 \mathrm{H}), 3.7-3.8(\mathrm{~m}, 2 \mathrm{H}), 3.73(\mathrm{~s}, 6 \mathrm{H}), 3.2(\mathrm{~m}, 2 \mathrm{H}), 3.0(\mathrm{~m}, 2 \mathrm{H}), 2.47(\mathrm{~s}, 3 \mathrm{H}), 2.35(\mathrm{~s}, 2 \mathrm{H}), 1.96-2.21$ $(\mathrm{m}, 2 \mathrm{H}), 1.8-1.9(\mathrm{~m}, 2 \mathrm{H}), 1.75(\mathrm{~m}, 2 \mathrm{H}) ;{ }^{13} \mathrm{C}$ NMR : $\delta 183.2,172.1,161.6,158.8,148.7,148.3$, 114.9 , 107.1, 102.6, 84.7, 70.2, 56.2, 56.2, 50.7, 38.4, 38.1, 31.9, 26.4, 24.9; MS : m/e=425 $\mathrm{M}^{+}$ Analysis calculated for $\mathrm{C}_{19} \mathrm{H}_{27} \mathrm{~N}_{5} \mathrm{O}_{4} . \mathrm{HCl} ; \mathrm{C}, 53.58 ; \mathrm{H}, 6.52 ; \mathrm{N}, 16.44$; Found : $\mathrm{C}, 53.53 ; \mathrm{H}, 6.34$; $\mathrm{N}, 16.43$.

\section{Acknowledgements}

We are very very thankful to Mr. S. Somasundaram, Mr. K. Raghavendra Chary, D. Srinivasa Rao and other members of analytical team of MSN Laboratories Limited, for their excellent support throughout the work. Co-operation from Research and Development and Manufacturing department colleagues is highly appreciated.

\section{References}

1. (a) Manoury, P. M.; Plessis Robinson Le.; U.S.Patent 4,315,007, 1982 ; Chem. Abstr. 1982, 96, p162737e. (b) Manoury P. M.; Binet, J. L.; Dumas, A. P.; Lefevre, F. B.; Cavero, I. J. Med. Chem. 1986, 29, 19. 
2. Nancy, F. R. U.S.Patent 4,661,491, 1987.

3. Reddy, M. S.; Kondal, R. B.; Kishore, K. M.; Rajan, S. T.; Venkatesh, M.; MSN Laboratories Ltd.; Indian Patent applications 1248/CHE/2005 dated 06.09.2005, 1811/CHE/2005 dated 12.12.2005 and 2270/CHE/2005 dated 07.12.2005.

4. Satyanarayana, R. M.; Kishore, K. M.; Sahadeva, R. M. ; WO 2006/137080, 2006.

5. Regis, B.; Kitamura, S. F.; Eur.Pat.Appl. 0663398, 1995 ; Chem.Abstr. 1995, 123, 314006g.

6. ICH Guidelines for Residual solvents by ICH Steering Committee ; Q3C, 1997. 